\title{
Administrative Aspects of Modernization in the Russian Regions
}

\author{
Yuri Grigorievich Volkov ${ }^{1}$, Igor Alexandrovich Guskov ${ }^{1}$, Magomedgabib Gasankhanovich Magomedov ${ }^{2}$, \\ Alexander Vasilievich Popov ${ }^{3} \&$ Rashid Dumalichevich Khunagov ${ }^{4}$ \\ ${ }^{1}$ Institute of Sociology and Regional Studies, Southern Federal University, Rostov-on-Don, Russian Federation \\ ${ }^{2}$ Don State Technical University, Rostov-on-Don, Russian Federation \\ ${ }^{3}$ Institute of Sociology and Regional Studies, Southern Federal University, Russian Federation \\ ${ }^{4}$ Adygea State University, Maikop, Russian Federation
}

Correspondence: Yury Grigorievich Volkov, Southern Federal University, Pushkinskaya street, 160, Rostov-on-Don, 344005, Russian Federation. Tel: 7-863-264-1755. E-mail: infoippk@sfedu.ru

Received: March 30, 2015 Accepted: April 20, 2015 Online Published: May 14, 2015

doi:10.5539/res.v7n7p277 URL: http://dx.doi.org/10.5539/res.v7n7p277

\begin{abstract}
Management of regions is a significant part of the current system of social management in Russia. It is beyond dispute that Russian regions vary greatly by economic, social, geo-climatic, and last but not least by ethno-cultural factors. The system of regional management of regions includes the mechanisms and instruments of relief, coordination and correction of different levels of administration. The article presents the trends of development of regions on the socioeconomic level. It also addresses the problems of current social and socioeconomic tendencies, and of advanced technologies in management.
\end{abstract}

Keywords: region management, modernization, human capital assets, modernization potential

\section{Introduction}

We can state that for a long time, modernization had a recurrent nature in the social development in Russian. It was apical, affected military and administrative aspects. But till now this concept was not very often associated with the formation and development of an efficient system of region management. In the circumstances of the escalating long-term social burden on Russian regions, it seems more attractive to delegate the solution of re-industrialization and post-industrialization problems, the formation of civil society institutions, the statement of the human person values, and improvement of the educational level to regions.

Regions have accumulated effective experience in countering threats and challenges and local problems. Modernization of the Russian society requires using the marked achievements for development, rather than adaptation to circumstances, for creating the rules, and conditions of regional and inter-regional interaction in order to strengthen the whole management system of Russian society, rather than for cost reduction or a regional race.

Studying the problem of regional administration, one must lay special emphasis on that fact that the main problem is the constant tendency to not differentiate the modernization of the Russian society as a whole and the processes and aspects of modernization at the local, regional level. We believe this is connected with the habit to describe regional development processes only from the point of view of national interests. Evidently, we can't expect the launch of effective regional modernization models out of the bounds of current center's strategy and policy in the financial, economic, social and political spheres.

On the other hand, we should stress that regional level of the modernization means the priority of national development. But there should be considered the wide variety and changeability of social and economic conditions at the regional level. Different regions have different modernization potentials, and therefore differentiated approach to making modernization emphases is required. Common sense dictates that the same management model can't be effectively applied to the same extent in the Central Russia Far East and in the Southern regions; they cannot adhere to unifying criteria. However, we should note that it doesn't mean that the cancellation of the political and legal regulators of the process of modernization.

The modernization in modern Russian flourishes and can be aligned with institutional, socio-structural and cultural changes. By this we mean that today Russian society is proved to be mostly ready for the modernization 
by the criterion of human potential.

On the other hand, we should emphasize that the concept of the modernization potential includes aside from economic criteria the factor of technological effectiveness and the professional potential. Moreover modernization potential is as well related to the current state of the management system in the specific region, and the ways the region interacts with the federal center and local communities. All of these factors should be understood in considered on the regional level of management system.

Not least important is the fact that modernization stimuli in the management system would be viewed through a reasonable estimate of the conditions existing in the regional environment. Excessive self-esteem, just as the position of passive waiting, slows down the process of modernization. A feeling of perpetual waiting occurs, which leads to the fact that either partial measures or partial changes are misrepresented as the modernization. In other case, modernization ranges far and wide influenced by the fact that the Russian society is unique and cannot have modernization patterns similar to the previously implemented modernization schemes.

Uniqueness should be mentioned to the extent that the Russian society, as a concentration of regions, is open to implementing different models of regional development. Without stepping across the line of management relativism, we must remember that the emphasis on the variability of regional development means the need to include a possibility of positions redefinition, continuous monitoring of the regional situation, apprehension and support of regional projects, understanding of the conventionality, and traditionalism and modernization in the Russian society into the priorities of the regional administration.

Despite the fact that the problem of the modernization potential of a region is very urgent, it has not yet been paid due attention of scientists. However, some works address the issues directly relevant to our problem. For example, some problems of modernization have been studied (Eisenstadt, 1966; Mergel, 2012; Beck, 1996), the theoretical and practical aspects of a region and regional development have been interpreted (Cohn-Bendit, 2012; Verhofstadt, 2009, 2012; Tabellini, 2005), the modernization of large territorial societies (Beck \& Grande, 2010), as well as special aspects of the regional potential (Posukhova \& Zayats, 2013) have been studied, and the subjects of regional development have been analyzed (Volkov, 2012).

\section{Research Methodology}

The study is based on the sociological theories revealing the essence of the process of modernization and social changes, the works by domestic and foreign scholars in the field of complex systems theory, management, decision-making, the systematic and result-oriented approaches containing the analysis and theoretical conclusions on the issues of regional management and management of large territorial societies.

An essential prerequisite for the development of a methodological foundation of the modern sociological research of region management problems is the acknowledgment of the socio-political process as an organizing principle in all spheres of social activity. This refers to the process of objective historical choice and changes in the management of the society, in its structures and institutions, as a set of procedures that determine the basic direction - the vector of development and modernization.

Authors of this article used a system of general scientific and special methods. The use of these methods is capable of providing paradigmatic vision of regional problems and the modernization potential of a region in terms of features of development of the Russian society. Along with the systematic approach, that provides a holistic view of the functional unity of individual elements of the region, the authors applied classic methods of analysis and synthesis, methodologies of learning the general and the particular, the primary and the secondary, the historical and the logical, and the dialectics of contradictory development of complex phenomena. The authors also used the peculiarities of the conceptual, attributive, and functional approaches to the study, considered the important features of synergetic interpretation of the processes of complex dynamic systems development, the results of the synthesis of historical and political, as well as empirical surveys, the materials of expert appraisements and analytical reports of all-Russian sociological researches.

\section{Results}

As for the modernization potential of a management system, we can note that, the modernization in Russian society has already taken place: admittedly and there has been taking place the accelerated modernization of the socialist type in the 1930s. And it has resulted in the urbanization of the Russian society, as well as the emersion of modern social classes. However, we agree that such processes are not too smooth to say that the process of social modernization has completed in the Russian society and the management system of regions requires overcoming regional inequalities and backwardness of individual regions.

We believe that regional communities have not yet finished their socio-cultural modernization processes, 
potential resources of self-development have not been identified, and regions still over-rely on the government of the state as a tool of macro-community interests' implementation. That fact that recognition of the specific role of the state in the modernization processes demands perceiving the potential of modernization as a criterion in the system of management. It is important to stress that the level of innovative developing and use of challenging management practices in the management system is high-priority for the system of regions management.

Sociological researches unambiguously show us that the current public consciousness is consolidated on the basis of the Russian values (Institute of sociology RAS, 2011). This circumstance makes it possible to understand the necessity and importance of regional and inter-regional vertical and horizontal models of development in the regional management system.

Differentiation of the Russian society into modernists and traditionalists can describe only the vertical section of the social life. We can state that it is quite relative in relation to regions, though, judging by the proportion of urban and rural population, there are regions, which tend to post-industrialization, and regions, which need the stage of re-industrialization.

The path of rapid modernization is acceptable for the regions management system as the most preferred for the elimination of regional inequalities. Since the Russian government cannot pump up certain regions with financial resources or create favorable conditions for them without imbalances of the regional development, the modernization potential of a management system is expressed in how and to what extent the management system is self-sufficient, and uses financial transfers effectively to solve problems; and how effective social practices, and legal and financial regulators are involved.

A popular myth states that the system of management is a self-isolated structure that is committed to very narrow strictly corporate ethics, and resists the modernization processes. But all these statements are not confirmed by actual sociological researches. There is no unambiguousness in choosing the management priorities: the objective - the formation of a modern country with appropriate level of production and life - is mostly the same in different regions. Only a degree of perception of modernization can vary from region to region, and is significantly higher in regions characterized by open market dynamic, and considerably lower in highly subsidized regions (Institute of sociology RAS, 2011).

With regard to the management system, the modernization policy is not questioned. But well-defined parameters of the modernization processes exist for particular regions.

Objective integral indicators of regions management are the gross domestic product, the level of corruption and crime, the level of education, science, the population health, and specific regional indicators that reflects the particular current problems of a concrete socio-cultural integrity: income of a person and family, consumer basket, minimum social standards, etc (Popov, 2001).

In this regard, it should be noted that an important feature of a management system is not to include the mechanisms of impelling to the technological process, but to influence on the minds and attitudes of the regional society for the purpose of social mobilization and achievement of the better results. Above all, this target refers to the regions management. That is because the extent of readiness of the regional society to implement modernization projects depends on how the management system is perceived, whether its value is determined by the extent, to which there is inertia, complacency, or the possibility of self-fulfillment of the region's potential.

Of course, the appraisal of modernization potential depends very heavily on the image of the region in the center, on the brand of the region, on the self-esteem of the regional life by the regional society, on the managerial mission as it is seen by regions management subjects. In the sense of devotion to the interests of the region, the reference is usually made to the origin of the regional leaders. At the same time, there is a predisposition to invite outside people who have proved themselves as experienced managers or technocrats.

Such "scissors" of preferences evidence that there is a not well established model of modernization influence in the public mind and that the regional life is often assessed solely by the subjectivist factor or by the degree of interaction with the center only.

The majority of the Russian regions show the symptoms of discontent with the current situation in the sphere of management and regional development. Therefore we should probably ask ourselves, what is to be changed in the regions management system to improve it. Judgments in this respect suggest that it is necessary to change both the condition of the regional management system, and the mobilization ability of the regional society. When it comes to the extent, in which the modernization potential is measured by a highly qualified managerial work, this indicator displays a real problem of generational change of the regions management system, as well as the change in the nature of managerial activities. 
It is obvious that for a real impact on the modernization process, managers-financiers cannot be expected to do miracles, as well as the outgoing generation of strong economic managers cannot be relied on.

The most positive tendency in modern Russian management system is the following: the increase of the level of professionalism in the field of economics, management and law. We can also state the tendency of rejuvenation of the staff in the system of management. All these aspects are of very big importance to understanding the significance of the self-development resource, the priority of the management performance criterion. Even if there is some disorientation depending on the region's specificity on this matter, it is not due to the intraregional differences. The degree of financial potential and endowment of regional projects take an important meaning.

The fact that regional differences result in the situation when being successful means getting to the category of donors, and thus greatly reducing the opportunities for modernization development can be explained as follows: The matter is that Russian donor regions usually are not the areas of modernization by technological parameters, i.e. they do not create surplus products. Reallocation of funds associated with the resource rents and with unique natural resources in possession of the regions determines the right of the government to redistribute income as national heritage. And the same way, concentration of financial resources in major metropolitan cities requires certain distribution by the government associated with returning profits to the regions where it was generated. Therefore, the modernization potential is measured by finding own development resources providing the region with the basis to take a position of certain independence and to build reputational capital in the influence on national processes.

Considering the readiness of the current system of management to realization of modern projects of modernization in Russian regions, one can say that the modernization potential and the efficiency of the management system strongly depends on the determination of strategy and tactics in the building constructive interactions with the system of local self-government and finding ways to support local initiatives. However, although the modernization readiness is not the only one condition for the realization of the modernization strategy in the region.

The capacity of modernization in the management system depends on the concrete objectives of social modernization. Modernization impact includes becoming of modern economy system, development of civil relations, the effectiveness of the governing bodies, and the increasing role of human capital.

As case studies show, the regional modernization potential is measured by a combination of technological, socio-structural, and subjective factors. If we assume that the modernization process affects all spheres of social life, it becomes clear that the managerial impact on the region is determined by socially regulated and socially innovative impacts of the management system.

It should be noted that the innovative capacity of the south of Russia is quite high. $63 \%$ of Russian citizens believe that innovations are a necessary condition for the future prosperity of Russia. At the same time, more than $50 \%$ believe that Russia could become a highly-developed power (Institute of Sociology RAS, 2001). But we should remember that the main "burden" falls to the management system of regions, and since we are dealing with average Russian rates, it may seem that the society is generally ready for modernization. Readiness for modernization in the regions, as identified above, depends on the modernization capacity of the region itself and the state of the regions management system.

It is clear that regional heterogeneity brings us to considering the modernization process as differently directed. In addition to the above, urgent tasks of socioeconomic development should not be matched with the long-term priorities. Almost all regions have approved a comprehensive program of socioeconomic development. Prokhozhev and Karmanova see its main drawback in relying on the existing sectoral structure of the economy (Prokhozhev \& Karmanova, 2004).

They note that this is the cause of the slowed down implementation of new technologies and appearance of new jobs. Herewith, the basic directions of sales have not been considered as well, which cumulatively increases the risk of growing costs. The authors disregard the fact that without reconstruction, re-industrialization, and return to the industries preserving high technological and professional potential, it is impossible to talk seriously about the modernization of regions. At both the country-wide level (MIC is an undeservedly neglected engine of industrialization), and the regional level, we should base on real, rather than newly created or projected points of economic growth.

We can conclude that according to sociological studies, every third resident in Russia supports the need to change the current situation (Institute of sociology RAS, 2012). Another thing is that the approval of changes means the need to determine, what could have the most effective impact on the regional modernization process, 
what can be the basis for assessing this impact of a management system in regional development. We should stress that the main criteria can be: the readiness of management system and the whole regional society for modernization, determination of the goals and priorities of modernization in a particular regional aspect and ratio of the regional society to the socially innovative and socially developmental role of management.

As the experience of regions management shows, modernization priorities are virtually shelved since the priorities of crisis management come to the fore, from this point of view. Application of the modernization potential of management results in standard values and practiced results achieved in the most developed regions of the country and abroad. The best results among the regions of Russia can be such references (Prokhozhev \& Karmanova, 2004).

It is obvious, that these figures are different for depressive, highly-developed, and moderately developed regions, but a single technique of calculating of the real changes is formed in the basis. With account of the fact that Russian regions have specific starting conditions for modernization and, accordingly, the modernization priorities differ depending on the socioeconomic and cultural development of the regions, it is important to carry out the modernization process within the framework of a uniform political and economic space, in which regions act as parts of the whole and function based on interregional relations.

For this reason, the position, considering that it is appropriate to take the indicators of more developed regions as a reference, is deficient. Actually, the grouping of regions by the identity of economic, social, and climatic conditions is closer to the real values. The proposed technique makes it obvious that the modernization potential of management is correlated with the specificity of regional development that importantly the development will be focused and sustainable, and that modernization is no longer a declaration. At the same time, regional processes bring us to the project activity, to the conscious choice of active inclusion of regions in the national modernization process.

We believe that the existing national and regional projects in various spheres of social life are real parameters of the entry of the Russian society in the process of modernization. We cannot ignore the fact that a management system is associated with the indicators of high quality of work, efficiency, competition, and the level of innovation. At the same time, having independent search strategies and team solutions of managerial problems, we can make the conclusion that the management system at the regional level needs the appraisal of management performance to be reasonable and fair. Reasonable appraisal means that it needs to account the actual conditions of regions and include the factor of external negative or positive impacts. And fair appraisal means that it must create in the region an atmosphere of social optimism, confidence in the future, because the breakdown into depressive and developing regions, donors and recipients significantly lowers the intensity of modernization activity in the society.

The difficulty is that the regions management acts under the scheme of "deferred expectations", i.e. modernization impulses are set by the centripetal tendencies, while regional development is largely dependent on proper regional factors and resources. It is obvious that the Federal Center acts appropriately, based on the accelerated development of the Far East region, since by virtue of demographics, professional capacity, staff shortage, the factor of remoteness, and the geopolitical risks, the strategy of the region support is effective. In addition, only the government is able to implement large-scale long-term infrastructural and technological projects.

In this situation, the syndrome of "regional passivity" is likely to worsen, as well as the desire to consider the prospects of regions solely on the basis of the possibility of implementation of mega-projects. A possible risk of pressure on the Federal Center by offering financially and organizationally unreasonable projects or "concentration" of crisis in the region associated with obtaining above-limit financial transfers should also be borne in mind.

Thereforeб it is necessary to differentiate the options of regional development, consider the goals and objectives of social development of regions depending on the prospects of specific economic and social activities. An important thing for enhancing the efficiency of regions management is to reject the "super scale" and form targeted regional programs related externally with the local problems, but giving the cumulative modernization effect.

\section{Conclusions}

Thus, the priority conditions of the modernization of the management system are implemented - an adequate balanced hierarchy of goals, achievement of which matches the regional resources. It is indicative that the greatest success is achieved in the regions, where either breakthrough technologies are implemented or the 
professional and technological potential of the region is used. With regard to the Rostov region and the Southern Federal District as a whole, it is necessary to set goals related to the development of the agricultural industry, mechanical engineering, and transport systems. In contrast to the Far East, the effect of "the construction from scratch" does not work, because the regional management is formed on the basis of regional societies having professional, cultural, and social traditions.

Undoubtedly, the "rootedness" factor and the knowledge of regional issues and investment activity, regional patriotism, interest in the development of the region as a concise contribution to the modernization of the country, which can have a real effect, are of great significance. It is important to understand that economic growth is effective if it offers the prospects of social well-being growth and positive cultural changes. Therefore, reliance on the regional resources forces not only to be guided by the logic of rational calculation, but also to share the idea of "common good" for the regional society. In other words, by refusing populist, obviously unrealistic goals providing a PR effect, but creating the risk of unfulfilled social expectations, regions management directs the activities to solving the challenges supported financially and technologically. We believe that it is necessary to include financial management and industrial management into the regions management system. This is justified, as modernization is a process of people management and change in the sense that the ongoing projects cannot be considered successful if social, cultural, and environmental consequences are not taken into account.

The problem is not to provide unification of regional development models, or to return industrialized regions, which was acceptable in the beginning of the XX century, but loses its appeal and effectiveness in the circumstances of involvement of regions into the search for new socioeconomic and socio-technological niches, for the possibility of finding incentives for development through the implementation and promotion of new products and services. It is obvious that achievement of these goals requires the development of skills of target programming and social expertise, which is associated with training and retraining managerial staff.

The system of management of Russian regions has proven its effectiveness with the expansion of intra-regional and inter-regional relations. This requires, firstly, migration to the quality indicators of managerial activity and introduction of cluster criteria of evaluation; secondly, combinations of the continuing anti-crisis trends with escalation of strategic projecting in management; thirdly, matching the standard values at the level of the national modernization process with the achieved indicators in regions management, which creates opportunities to strengthen and enhance the independence of regions in implementation of modernization strategies.

\section{References}

Beck, U. (1996). The reinvention of politics—Rethinking modernity in the global social order. Cambridge: Polity Press.

Beck, U., \& Cohn-Bendit, D. (2012). Wir sind Europa! Manifest zur Neugründung Europas von unten. Retrieved from http://www.cohn-bendit.eu/de/ct/284-Wir-sind-Europa\%21-\#center

Beck, U., \& Grande, E. (2010). Varieties of second modernity: Extra-European and European experiences and perspectives. British Journal of Sociology, 61(3), 406-638.

Eisenstadt, S. N. (1966). Modernization: Protest and change. Englewood Cliffs, New Jersey: Prentice-Hall.

Foundations of modern social management (p. 72). (2000). Moscow: Economy.

Is the Russian society ready to modernize (pp. 168-180)? (2011). Moscow: Institute of sociology RAS.

Mergel, T. (2012). Modernization-European History Online. Retrieved from http://ieg-ego.eu/en/threads/models-and-stereotypes/modernization/thomas-mergel-modernization

Toschenko, Z. T. (Ed.). (2013). New ideas in sociology (pp. 108-115). Moscow: UNITY-DANA.

Popov, A. V. (2001). Regional administration. Rostov-on-Don: NCSC HS.

Posukhova, O., \& Zayats, P. (2014). Social engineering as a mechanism of optimization of human resources management in Rostov region. Middle East Journal of Scientific Research, 19(3), 424-428.

Prokhozhev, A. A., \& Karmanov, I. A. (2004). Regions of Russia: Social development and security. Moscow: News.

Reforming Russia (Vol. 11, pp. 30-120). (2012). Moscow: The new chronograph.

Tabellini, G. (2005). Culture and Institutions: Economic development in the regions of Europe. IGIER, Università Bocconi, Working Paper, 292.

Institute of Sociology RAS. (2001). The modernization and integration potential of regions of the Caucasus (p. 
213). Rostov-on-Don: Socio-humanitarian Knowledge.

Institute of Sociology RAS. (2012). Twenty years of reforms for Russia by the residents of Rostov region (p. 35).

Rostov-on-Don: Antaeus.

Verhofstadt, G. (2009). Sortir de crise: Comment l'Europe peut sauver le monde. In Essais Sciences humaines (Arles/Bruxelles, Actes Sud/André Versaille Éditeur, coll. p. 252).

Verhofstadt, G. (2012). Debout l'Europe! (avec Daniel Cohn-Bendit, p. 158). Bruxelles, Belgique, André Versaille éditeur.

Volkov, Y. (2013). Creative Tendencies in Regional Elites' Activity. World Applied Sciences Journal, 28(2), 180-184.

\section{Copyrights}

Copyright for this article is retained by the author(s), with first publication rights granted to the journal.

This is an open-access article distributed under the terms and conditions of the Creative Commons Attribution license (http://creativecommons.org/licenses/by/3.0/). 